\title{
Symmetrical and asymmetrical sources of variance in temporal generalization
}

\author{
RUSSELL M. CHURCH and KEVIN D. MILLER \\ Brown University, Providence, Rhode Island \\ WARREN H. MECK \\ Columbia University, New York, New York \\ and \\ JOHN GIBBON \\ New York State Psychiatric Institute and Columbia University, New York, New York
}

\begin{abstract}
Ten rats were trained in a temporal generalization task (the peak procedure) with variations in the time of reinforcement, the intertrial interval, and the mean and variance of the duration of nonfood trials. There were three types of asymmetry in the temporal generalization gradients: positive skew, secondary rise, and positive asymptote. Asymmetrical gradients can occur as a result of asymmetrical sources of variance, multiplicative combinations of symmetrical sources of variance, and effects of anticipation of the end of a trial and the conditions of the next trial. Ten additional rats were trained with a single time of reinforcement, a limited time of reinforcement availability, long and fixed durations of nonfood trials, and a nonresponse requirement for ending a trial. These conditions markedly reduced all asymmetrical sources of variance and led to very symmetrical gradients. These results demonstrate that none of the asymmetrical sources of variance necessarily has a substantial influence on observed temporal generalization gradients.
\end{abstract}

A temporal generalization procedure is one in which reinforcement of a response depends on the duration of a stimulus. In one variant of the procedure, a signal occurs for a duration of between 2 and $8 \mathrm{sec}$. If a 4 -sec signal occurs, then a lever response by a rat is reinforced, but if the signal is shorter or longer than $4 \mathrm{sec}$, the response is not reinforced. The probability of a response increases as a function of time to a maximum near $4 \mathrm{sec}$ and then decreases (Church \& Gibbon, 1982). Another variant of a temporal generalization procedure originated by Catania (1970) has been called the peak procedure by Roberts (1981). On some trials (food trials), a signal occurs and the first response after a fixed duration (such as $40 \mathrm{sec}$ ) is reinforced. On other trials (nonfood trials), the signal occurs for a much longer time and no response is reinforced. The response rate increases as a function of time to a maximum near the time food is sometimes available and then decreases. The function relating response probability or rate to the duration of a stimulus will be referred to as the temporal generalization function. It usually has a maximum near the reinforced stimulus duration and, although it is reasonably symmetrical around this value, usually has some positive skew.

This research was supported by grants from the National Institute of Mental Health (R01-MH44234) and the National Science Foundation (BNS 8418293). Correspondence concerning this article should be addressed to Russell M. Church, Department of Psychology, Brown University, Providence, RI 02902. Parts of this paper were presented at a meeting of the Psychonomic Society, Chicago, November 11, 1988.
An information-processing model of temporal generalization has been proposed that contains three major components: internal clock, reference memory, and comparator (Gibbon \& Church, 1984). When the value in the internal clock is similar enough to the value sampled from reference memory, a response occurs. The results of temporal generalization procedures demonstrate that animals can estimate time intervals, but they do so with some error. Analysis of that error has provided information about the process used for the estimation of time intervals. The estimate of a time interval may reflect sources of variance in the clock, memory, or comparator (Gibbon, Church, \& Meck, 1984). The estimate may also reflect sources of variance that are independent of the timing process (Church \& Gibbon, 1982; Meck \& Church, 1984; Roberts, 1981).

No single source of variance has been adequate to account for the performance of animals on temporal generalization tasks. A single source that produces symmetrical variance, such as the threshold value used in the comparator, does not account for the small amount of asymmetry that is always present in temporal generalization functions. A single source of asymmetrical variance, such as clock speed, is also insufficient to account for the shape of temporal generalization functions. The sources of asymmetrical variance that have been proposed do not account for the considerable symmetry of the temporal generalization functions, and none of them apply to all three types of asymmetry that have been observed: (1) the function may be positively skewed (Gibbon et al., 1984), 
(2) it may begin near the baseline but have an asymptotic value greater than the baseline (Roberts, 1981), or (3) it may have a secondary increase near the end of the trial (unpublished data from our laboratory). In reviewing the information available at the time, Gibbon and Church (1984) concluded that at least two sources of variance, one symmetrical and one asymmetrical, were required to account for the performance of animals on temporal generalization tasks.

The present experiments were designed to identify the variables responsible for the various types of asymmetry in temporal generalization functions and to attempt to eliminate them. If animals can generate symmetrical temporal generalization functions, then temporal generalization does not require any of the various sources of asymmetrical variance.

\section{EXPERIMENT 1: INTERTRIAL DURATION}

Performance in many discrimination tasks is enhanced by long intervals between trials. For the acquisition of autoshaping (Gibbon \& Balsam, 1981) and for asymptotic performance of the conditioned emotional response (Stein, Sidman, \& Brady, 1958), the ratio of the intertrial inter$\mathrm{val}$ (ITI) to the duration of the trial appears to be the relevant variable. The present experiment was designed to determine the effect of the ITI on performance of a temporal generalization task.

\section{Method}

\section{Subjects}

The subjects were 10 experimentally naive male albino Norway rats (Charles River VAF) about $\mathbf{1 0 0}$ days old when the experiment began. They were housed in individual cages and fed a daily ration of about $14 \mathrm{~g}$ of ground rat chow mixed with about $25 \mathrm{ml}$ of water.

\section{Apparatus}

Ten lever boxes $(23 \times 20 \times 22 \mathrm{~cm})$ were used in the experiment. The roof and side panels were transparent acrylic, the front and back walls were aluminum, and the floor was constructed from 16 parallel stainless steel bars. Two retractable stainless steel levers projected through the front panel on either side of the food cup. The levers in Boxes 1-6 were $1.6 \times 4.6 \mathrm{~cm}$ wide and were located $3.8 \mathrm{~cm}$ above the grid floor (Gerbrands Model 6311). The levers in Boxes 7-10 were $2.5 \times 5.0 \mathrm{~cm}$ wide and were located $5.0 \mathrm{~cm}$ above the grid floor (BRS/LVE Model 123-07). A pellet dispenser delivered 45-mg Noyes (Improved Formula A) food pellets through an opening in the front panel to a food cup. A 140 -ml glass water bottle hung from the back wall of the chamber. All of the boxes had a houselight with a nominal candle power of 3 (General Electric Co. miniature lamps, Model 301) attached to the middle of the back wall of the chamber. A noise generator (Grason-Stadler Co. Model 901B) was used to provide white noise of about $75 \mathrm{~dB}$ to the individual boxes. Each lever box was enclosed in an insulation board chamber designed to minimize outside light and sound, and each chamber was equipped with a ventilation fan and a small observation window. A Minc-23 computer (Digital Equipment Corporation) connected to a custom-built input-output interface controlled the experimental apparatus and recorded the data.

\section{Procedure}

Pretraining. A session began with the illumination of the houselight and the insertion of the left lever. Sixty responses were rein- forced with a food pellet, then the light was turned off and the lever retracted. Pretraining continued until all 60 responses were completed within $30 \mathrm{~min}$ on 2 consecutive days.

Training (Sessions $1-60$ ). On a random half of the trials (food trials), a signal was begun, the first response after the critical time ( 10 or $20 \mathrm{sec}$ ) was followed by food, then the signal terminated and the lever retracted. On the other trials (nonfood trials), there was no food and after $120 \mathrm{sec}$, the signal terminated and the lever retracted. The ITI was $2 \mathrm{sec}$. For half the rats, light was the signal for the 10-sec trials and noise was the signal for the 20 -sec trials. For the other half of the rats, noise was the signal for the $10-\mathrm{sec}$ trials and light was the signal for the $20-\mathrm{sec}$ trials. The 10- and 20 -sec trials strictly alternated throughout the session. Each session lasted for $2 \mathrm{~h}$.

Testing (Sessions 61 -75). The ITI was $2 \mathrm{sec}$ for the first five sessions, $120 \mathrm{sec}$ for the next five sessions, and $2 \mathrm{sec}$ for the final five sessions.

Data analysis. The mean response rate was calculated in 1-sec intervals for each rat for each signal on each block of sessions. From these functions, the first time that the response rate increased above $70 \%$ of the maximum response rate and the last time that it decreased below $70 \%$ of the maximum response rate were determined. The time of the maximum response rate (peak time) was defined as halfway between these two points, and the spread was defined as the difference between these two points. Iterative procedures (e.g., Roberts, 1981) and model-fitting procedures (e.g., Gibbon et al., 1984) would undoubtedly produce results very similar to each other and to the present simple empirical measure that provides values for both center and spread. Analyses of variance (ANOVAs) were conducted on peak time, spread, and the logarithm of the response rates.

\section{Results}

The mean response rate on nonfood trials as a function of time since the trial began is shown for the five sessions of testing with 2-, 120-, and 2-sec ITIs (Figure 1).

In each set of five sessions, the mean response rate increased to a maximum near the time that food was sometimes available and then decreased in a slightly asymmetrical manner. The mean peak times (and standard errors of the mean) on trials with the signal associated with food after $10 \mathrm{sec}$ were $12.0(0.4), 12.5(0.4)$, and $12.3(0.3) \mathrm{sec}$ with the 2-, 120-, and 2-sec ITIs, respectively; the peak times on trials with the signal associated with food after $20 \mathrm{sec}$ were $19.7(0.6), 20.3(0.5)$, and $17.4(1.1) \mathrm{sec}$ with the 2-, 120-, and 2-sec ITIs, respectively. Peak time was related to the time of reinforcement $[F(1,8)=187.2, p<$ $.001]$, but it was not systematically related to the length of the ITI or to signal modality. The ratio of peak time on 20-sec nonfood trials to peak time on 10-sec nonfood trials was about 1.6 , less than $2.0[t(9)=7.7, p<.001]$. The times of the peak on trials with the signal associated with food after $10 \mathrm{sec}$ and $20 \mathrm{sec}$ were not significantly correlated $[r(8)=.37]$. The spread was positively related to the time of reinforcement $[F(1,8)=29.5, p<.001]$, but the ratio was about 1.4 , less than $2.0[t(9)=4.3$, $p<.001]$. The mean ratio of spread to time of the peak was .83 for the 10 -sec signal, which was not significantly different from .77 for the 20 -sec signal $[F(1,8)=1.5]$.

In all cases, after reaching a maximum near the time food was sometimes available, the mean response rate decreased to a minimum of about $60 \mathrm{sec}$ and then increased gradually for the remainder of the trial. (The inserts in Figure 1 

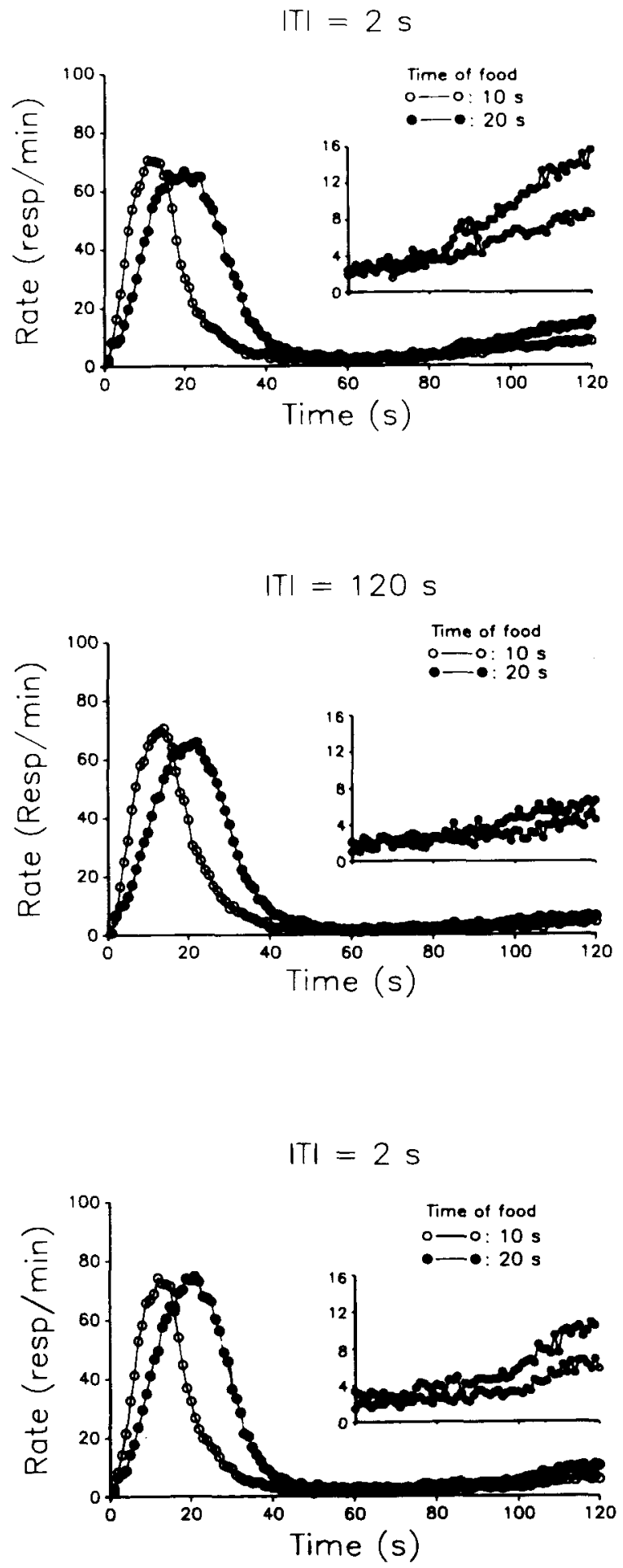

Figure 1. Experiment 1: The mean response rate on nonfood trials as a function of time since the signal began for five sessions of testing with a 2-sec intertrial interval (TT) (Sessions 61-65 in top panel), a 120-sec ITI (Sessions 66-70 in center panel), and a 2-sec ITI (Sessions 71-75 in bottom panel). Open circles are for the signal associated with food at $10 \mathrm{sec}$, and solid circles are for the signal associated with food at 20 sec. provide an expanded scale of response rates.) The mean response rate increased from 2.0 responses/min during the middle $10 \mathrm{sec}$ (Seconds $61-70$ ) to 5.7 responses/min during the final $10 \mathrm{sec}$ (Seconds $111-120)[F(1,8)=26.3$, $p<.001]$. The mean response rate increased from 2.1 to 7.4 responses $/ \mathrm{min}$ from the middle to the final $10 \mathrm{sec}$ for the 20-sec functions, and it increased from 1.9 to 4.4 responses/min from the middle to the final $10 \mathrm{sec}$ for the 10 -sec functions. The increase was greater for the 20-sec functions than for the 10 -sec functions $[F(1,8)=6.2]$, but it was not related to the ITI duration $[F(2,16)=0.7]$. The geometric mean response rate during the middle and final $10 \mathrm{sec}$ was greater for the $2-\mathrm{sec}$ ITI than for the 120sec ITI $[F(2,16)=9.3, p<.01]$ and greater for the 20 -sec signal than for the 10-sec signal $[F(1,8)=15.7$, $p<.01]$.

\section{Discussion}

The mean response rate as a function of time since a signal was begun increased to a maximum near the time that food was sometimes available $(10$ or $20 \mathrm{sec})$ and then decreased. Although the mean peak time and its spread were strongly related to the time of reinforcement, the ratios were reliably less than 2.0 . This may have been due to a latency to begin timing or to a failure to discriminate on some trials. The similarity of the ratios of the spread to time of peak on the 10- and 20-sec trials is evidence for the scalar property. The functions were positively skewed and, except for the magnitude of the secondary increase, were unaffected by the duration of the ITI.

A secondary increase in the function began after about $60 \mathrm{sec}$ and continued to the end of the trial. There are two plausible sources of reinforcement for this response pattern: the secondary reinforcement of the onset of the intertrial stimulus, and the primary reinforcement of food on the next trial. This secondary increase was greater on the 20-sec nonfood trials than on the 10-sec nonfood trials, probably because the 20 -sec nonfood trials were always followed by a 10-sec trial, while the 10-sec nonfood trials were always followed by a 20-sec trial. Although the strict alternation design used cannot rule out the time of reinforcement on the current trial as the relevant variable, the secondary increase in response rate was probably at least partly in anticipation of the conditions of reinforcement on the next trial. Such an increase would occur for the same reasons as the increase prior to the 10 - or 20 -sec time that reinforcement was sometimes available.

The length of the ITI did not appear to affect the first $60 \mathrm{sec}$ of the temporal generalization function and did not affect the peak time, but the magnitude of the secondary increase was significantly greater when the ITI was short $(2 \mathrm{sec})$ than when it was long $(120 \mathrm{sec})$. This also suggests that the secondary increase was at least partly in anticipation of the conditions of reinforcement on the next trial. But the magnitude of the difference in the secondary increase due to a large difference in ITI (2 vs. $120 \mathrm{sec}$ ) was not substantial. 
The temporal generalization function may be more affected by trial duration than by ITI.

\section{EXPERIMENT 2: TRIAL DURATION}

In the previous experiment, with a relatively long $(120 \mathrm{sec})$ trial duration, it appeared that rats anticipated the end of a trial of fixed duration. This anticipation was demonstrated by a secondary rise in the temporal generalization function. The first maximum reflects the timing of the food and the second maximum reflects the duration of the trial. This may be an example of simultaneous temporal processing in which the rat times two different intervals beginning at trial onset.

If the duration of the trial were much shorter (such as $40 \mathrm{sec}$ ), the responding due to timing of the food and the responding due to timing of the end of the trial might occur simultaneously, so that a more positively skewed temporal generalization function might occur. Simultaneous timing of two signals has been demonstrated in previous experiments (Meck \& Church, 1984; Olton, Wenk, Church, \& Meck, 1988).

If the trial duration were not constant but random (an exponentially distributed waiting-time distribution), then the probability of the trial ending would be independent of the time since the trial began. An objectively random schedule appears to be random to animals since their behavior becomes constant as a function of time (LaBarbera \& Church, 1974; Libby \& Church, 1975). With a random duration trial, the secondary rise in the temporal generalization function should be eliminated since the time that the trial will end and the time that food will be available on the next trial are unaffected by time since the present trial began.

\section{Method \\ Subjects and Apparatus \\ The subjects were 10 rats used in Experiment 1, and the appara- tus was the same as that used in Experiment 1.}

\section{Procedure}

Sessions 76-90. The training procedure was the same as that used in training in Experiment 1, except the trial duration on nonfood trials was not a constant $120 \mathrm{sec}$. For half of the rats (Group 1), nonfood trials ended after a constant $40 \mathrm{sec}$. For the other half of the rats (Group 2), nonfood trials ended after an exponentially distributed random duration calculated to the nearest millisecond. The nonfood trials with a 10 -sec signal lasted for $10 \mathrm{sec}$ plus an exponentially distributed random waiting time with a mean of $110 \mathrm{sec}$, and the nonfood trials with a 20 -sec signal lasted for $20 \mathrm{sec}$ plus an exponentially distributed random waiting time with a mean of $100 \mathrm{sec}$, so that the mean nonfood trial duration was $120 \mathrm{sec}$.

Sessions 91-105. The conditions of training of the rats in Groups 1 and 2 were reversed.

\section{Results}

The mean response rate on nonfood trials as a function of time since the trial began is shown for the last five sessions of training in Figure 2.
As in Experiment 1, the mean response rate increased to a maximum near the time that food was sometimes available and then decreased in a slightly asymmetrical manner. The mean peak times (and standard errors of the mean) on trials with the signal associated with food after $10 \mathrm{sec}$ were $12.1(0.3)$ and $11.8(0.3) \mathrm{sec}$ with the fixed and random times of food, respectively; the peak times on trials with the signal associated with food after $20 \mathrm{sec}$ were $21.8(0.9)$ and $19.2(0.8) \mathrm{sec}$ with the fixed and random times of food, respectively. Peak time was related to the time of reinforcement $[F(1,8)=156.6, p<.001]$. There was also a significant 3-way interaction between group, time of food ( $10 \mathrm{vs.} 20 \mathrm{sec}$ ), and trial duration (fixed vs. random) $[F(1,8)=9.7, p=.01]$. The estimate of the peak time in Group 1 with food available at $20 \mathrm{sec}$ and a fixed trial duration was particularly high because of the asymmetrical function. The spread was positively related to the time of reinforcement $[F(1,8)=35.3$, $p<.001]$, but not to other factors. The mean ratio of the spread to the time of the peak was .57 for the 10 -sec signal and .56 for the 20 -sec signal $[F(1,8)=.04]$.

The geometric mean response rate during Seconds 31-40 was higher when the nonfood trial duration was $40 \mathrm{sec}$ than when the nonfood trial duration was a random $120 \mathrm{sec}$ ( 19.9 vs. 7.3 responses $/ \mathrm{min}$ ), and it was higher when the food was sometimes delivered after $20 \mathrm{sec}$ than when it was sometimes delivered after $10 \mathrm{sec}(17.1 \mathrm{vs} .8 .6 \mathrm{sec})$. An ANOVA on the logarithm of the response rates showed both differences to be significant $[F(1,8)=76.6$ and 58.6, $p<.001]$.

In contrast to the first experiment, with random trial durations there was no significant increase in geometric mean response rate from the middle (Seconds 61-70) to the end (Seconds 111-120) of the function (2.4 vs. 2.7 responses $/ \mathrm{min})[F(1,9)=0.3$, n.s. $]$. The geometric mean response rate from the middle and the end was 3.8 and $3.5 \mathrm{responses} / \mathrm{min}$ for the $20-\mathrm{sec}$ functions and 1.5 and 2.0 responses $/ \mathrm{min}$ for the $10-\mathrm{sec}$ functions. The mean rate was higher in the 20 -sec conditions than in the 10 -sec conditions $[F(1,8)=8.8, p<.02]$.

\section{Discussion}

The short $(40-\mathrm{sec})$ constant trial duration produced a temporal generalization gradient with a substantially greater positive skew than the longer $(120-\mathrm{sec})$ constant trial duration used in Experiment 1. With a long constant trial duration, responding due to the time of food may occur first and responding due to the time of the end of the trial may occur later; with a short constant trial duration, responding due to the timing of these two events may occur simultaneously. The combination of the timing of the food with the timing of the end of the trial at $40 \mathrm{sec}$ may produce the positively skewed function.

The longer $(120-\mathrm{sec})$ random trial duration produced a temporal generalization gradient with a relatively flat asymptotic response rate well above zero. With random trial durations, the probability of a trial ending at any par- 

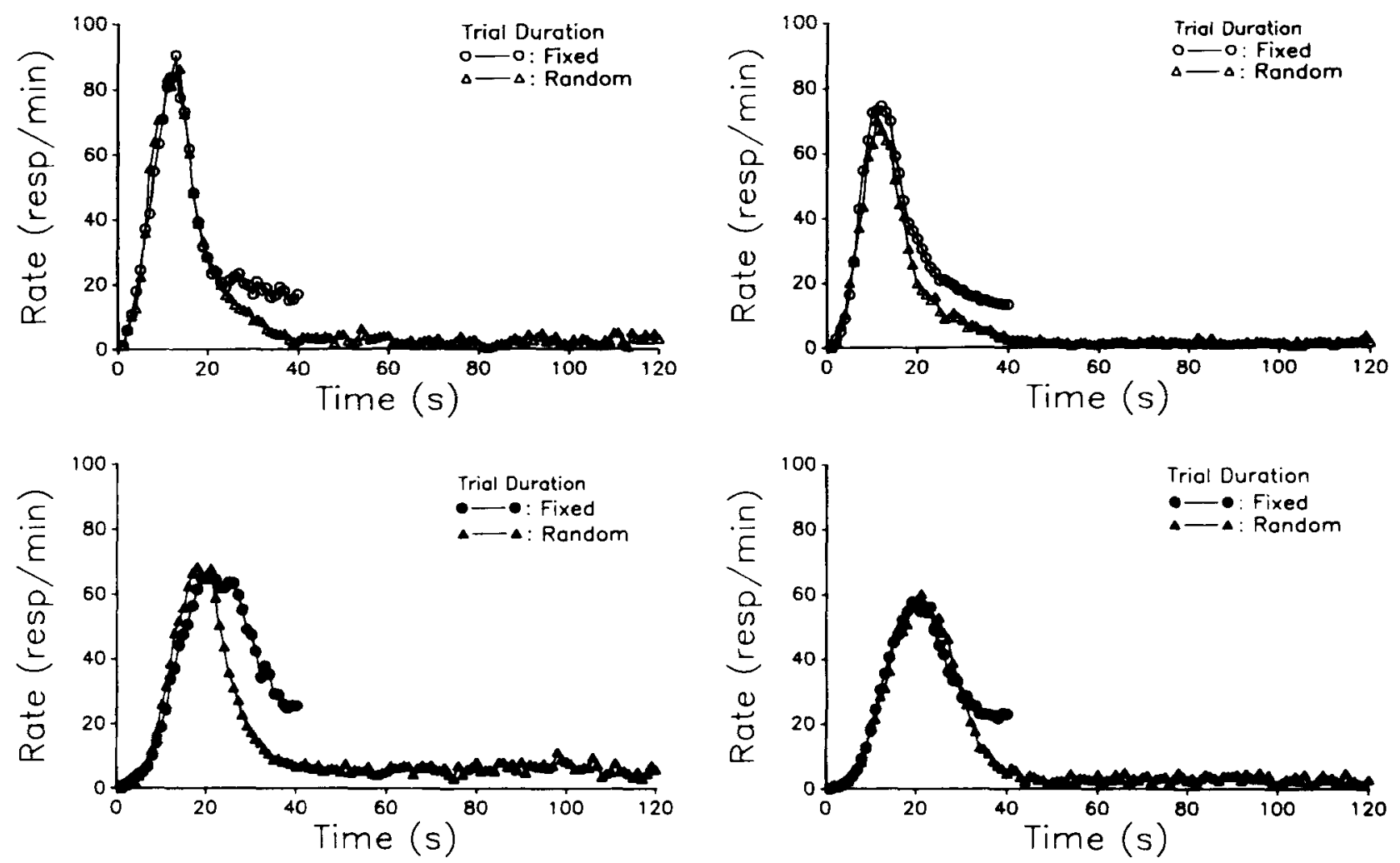

Figure 2. Experiment 2: The mean response rate on nonfood trials as a function of time since the signal began for the final five sessions of testing with a 40-sec fixed trial duration (circles) and a 120-sec random trial duration (triangles). The functions for signals associated with food at 10 sec are shown in the top panels; the functions for signals associated with food at 20 sec are shown in the bottom panels. The left panels are for Group 1, and the right panels are for Group 2.

ticular time is unaffected by the time since the signal began, and this may lead to a relatively constant mean response rate. If this relatively constant mean response rate reflects the expected time to the end of the current trial and the conditions of the next trial, the mean response rate would be expected to be higher when food on the next trial was scheduled to occur after $10 \mathrm{sec}$ rather than after $20 \mathrm{sec}$. The strict alternation between $10-$ and $20-\mathrm{sec}$ trials in this experiment thus would lead to a higher mean response rate on $20-\mathrm{sec}$ trials than on $10-\mathrm{sec}$ trials. The conditions of the present trial are critical for the form of the function (rising or flat), but the conditions of the next trial are critical for the magnitude of the function.

The present interpretation of the two types of asymmetry observed in this experiment is different from the interpretations that have previously been proposed. Since scalar timing theory does not account for a constant asymptotic rate greater than zero, it has been proposed previously that this is due to nontiming factors. One psychological process that could lead to such performance would be inattention to signal duration, along with the assumption that there is some constant rate of response given inattention (Church \& Gibbon, 1982; Meck \& Church, 1984). This produces an operant level of responding that combines additively with responding due to the timing process. When the function relating response rate to the time since the signal began starts near zero, reaches a maximum near the time of reinforcement, and then falls to an asymptotic level above zero, one may assume that inattention begins only after some upper threshold of time has passed since the signal began. The observed function has also been fit by a combination of a normal distribution and a ramp function (Roberts, 1981).

The skewed functions in the past have been accounted for in terms of scalar sources of variance that produce such results. For example, symmetrical variance in the pacemaker, asymmetrical variance in memory storage or threshold, and multiplicative symmetrical sources of variance all lead to skewed functions (Gibbon \& Church, 1990; Gibbon et al., 1984). A multiplicative combination of two sources of symmetrical variance, such as memory encoding and response threshold, has accounted for about $98 \%$ of the variance, but there are several problems with the previous explanations of the asymmetrical temporal generalization gradients.

First, alternative sets of variance sources were equally able to provide good fits of the observed data, so the analysis of individual trial data rather than mean data may 
be required to evaluate separate contributions (Gibbon \& Church, 1990). Second, there was no rational basis for knowing in advance which sources of variance would be required to fit the results of an experiment. For example, some data required sources of variance (such as clock variance) that produced skewed data, and others required sources of variance (such as inattention) that produced above-zero asymptotes, but there was no a priori basis for assuming that the conditions that led to the skewed data increased clock variance or that the conditions that led to the above-zero asymptotes decreased attention. Finally, none of the previous explanations have dealt with the secondary increase.

The present experiments suggest an alternative interpretation of some asymmetries previously observed in temporal generalization gradients; that is, they are due to expectations of the time of the end of the trial and the treatment on the next trial. When the end of the trial is constant and distant, there will be a secondary increase in the function near the end of the trial; when the end of the trial is fixed and close, there will be a positive skew; and when the end of the trial is random, there will be a constant asymptotic level above zero. Instead of attempting to prove these conjectures, Experiment 3 was designed to eliminate all sources of asymmetry in the temporal generalization gradient and then to attempt to account for the sources of variance in the resulting gradient that would be uncontaminated by factors other than the timing of food on the present trial.

\section{EXPERIMENT 3: ELIMINATION OF SOURCES OF ASYMMETRIC VARIANCE}

The assumption was that responses in anticipation of the time of the end of the trial and the treatment of the next trial could not be eliminated, but their location could be controlled. With a random trial duration, responses in anticipation of the end of the trial would be distributed throughout the trial, and some of these responses would be intermingled with responses controlled by the expected time of reinforcement on the current trial. With short constant trial durations, responses in anticipation of the end of the trial would also be intermingled with responses controlled by the expected time of reinforcement. But with a long constant trial duration, responses in anticipation of the next trial would be distributed near the end of the trial, where they would be clearly separate from the main temporal generalization function.

In addition to asymmetries produced by anticipation of the end of the trial or the treatment on the next trial, there are three other possible sources of asymmetry. First, any confusion between the two time intervals used in the previous experiments (10 and $20 \mathrm{sec}$ ) would produce an asymmetry, since a mixture of two symmetrical distributions is not generally symmetrical. Therefore, only one signal and time of reinforcement was used. Second, there is the possibility that animals may search for food in time much as they search for food in space. If such checking occurred on a food trial in which the animal had been unresponsive, there would have been occasional reinforcement of checking responses far from the time of reinforcement. To eliminate the possibility of reinforcement of checking responses, reinforcement was available on food trials only for responses that occurred between 18.5 and $21.5 \mathrm{sec}$ (limited hold). Third, responses that occurred near the end of a trial may have been superstitiously reinforced by the end of the trial. Therefore, a delay procedure was used so that a trial did not end unless there was an absence of responding in the previous $5 \mathrm{sec}$. A short ITI was used to maximize the amount of information per hour and to minimize the possibility of autoshaping.

\section{Subjects and Apparatus \\ Ten experimentally naive male albino Norway rats (Charles River CD) approximately 80 days old when the experiment began were used in the experiment. The apparatus was the same as that described in Experiment 1.}

\section{Procedure}

Pretraining. Pretraining was the same as that described in Experiment 1 .

Training (Days 1-30). After a 2-sec ITI, a trial began with the onset of a noise. On a random half of the trials (food trials), the first response after $20 \mathrm{sec}$ was followed by food, termination of the signal, and retraction of the lever. On the other trials (nonfood trials), there was no food and a trial lasted $20 \mathrm{sec}$ plus a random waiting time with a mean of $60 \mathrm{sec}$. At the end of the trial, the signal terminated and the lever retracted. Each session lasted for $2 \mathrm{~h}$ $15 \mathrm{~min}$.

Training (Days 31-60). On food trials, the procedure was the same as on food trials during Days 1-30, except food was available only for a brief time (a limited hold) with a mean of $20 \mathrm{sec}$. If a response occurred during that brief time, food was delivered and the trial ended; if the animal failed to respond during this brief time, the trial continued as during a nonfood trial, but the results of the trial were not used in the data analysis. The limited hold was $10 \mathrm{sec}$ on Days 31-35, and it was reduced by $2 \mathrm{sec}$ every 5 days until Days 51-60, on which it was reduced by $1 \mathrm{sec}$, from 4 to $3 \mathrm{sec}$. On these days, a response between 18.5 and $21.5 \mathrm{sec}$ was required for reinforcement. On nonfood trials, the procedure was the same as on nonfood trials during Days 1-30, except that trials were extended by $5 \mathrm{sec}$ whenever a response occurred within $5 \mathrm{sec}$ of a scheduled termination.

Testing (Days 61-75). Training was continued as during Days 56-60, except that the nonfood trials were $120 \mathrm{sec}$ in duration on all trials.

\section{Results}

The mean response rate as a function of time since the trial began is shown for the last five sessions of testing in Figure 3. The mean rate increased to a maximum at 18.9 (0.7) sec, which was near the time that reinforcement was first available $(18.5 \mathrm{sec})$, and then it decreased in a fairly symmetrical manner. The degree of symmetry is shown by the use of open squares to replot the mean response rate from 36 to $19 \mathrm{sec}$ on top of the mean response rate from 1 to $18 \mathrm{sec}$. Any systematic discrepancy between the two functions is very small. The mean ratio of the spread to the time of the peak was .53 . 


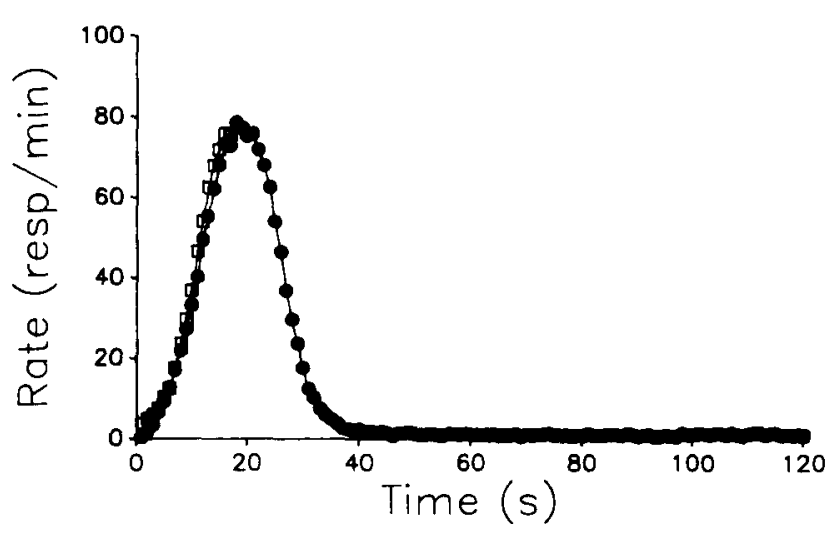

Figure 3. Experiment 3: The mean response rate on nonfood trials as a function of time. The degree of symmetry is shown by replotting the function from $\mathbf{4 0}$ to $20 \mathrm{sec}$ (open squares) on the function from 0 to $20 \mathrm{sec}$ (solid circles).

The time of the peak (defined as halfway between the first time that the response rate increased above $70 \%$ of the maximum response rate and the last time it decreased below $70 \%$ of the maximum response rate) was close to the 1 -sec interval with the highest response rate. The mean of the discrepancies in these measures was $.25 \mathrm{sec}$. This is a measure of the degree of symmetry of the temporal generalization function.

\section{Discussion}

The procedure in Experiment 3 was designed to reduce the effect of anticipation of the next trial on performance on the current trial and to reduce the reinforcement of checking responses. The results were that the temporal generalization function was much more symmetrical than the functions generated by Experiments 1 or 2 or by previous experiments (Gibbon et al., 1984). Further research on the effects of various independent variables on the temporal generalization gradient should normally be conducted on symmetrical gradients in which the performance on a given trial is relatively unaffected by the conditions of the next trial.

The near symmetry observed in our best data strongly suggests that the contribution of asymmetrical sources of variance (such as clock rate or inattention above a threshold) may be small in magnitude and that there is at least one major symmetrical source of variance underlying the temporal generalization functions. We have proposed earlier that temporal generalization functions result from a timing system with several Gaussian sources of variance. It is readily shown that, if only one of these is operating, the result is symmetry in the function (e.g., Gibbon \& Church, 1984; Gibbon et al., 1984; see also Gibbon, 1991, for an overview). However, if several of them are operating and if their combined effect on response probability is due to a multiplication (or division), the result is a positive skew in the temporal generalization function. Thus, random variables, which are themselves symmetric but are multiplied or divided in their resulting effect on response probability, induce skew in the outcome (Gibbon, 1981). The observed symmetry in the temporal generalization function appears to imply only one major source of variance.

Sources of variance that combine in an additive manner do not induce asymmetry in the peak function. An example of such a source is latency to begin timing. For simplicity, we restrict our attention here to two major alternative sources of variance: variance in the timing itself (or the memory for the criterion time) and variance in the response comparison system (threshold). The distinction between memory for time and thresholds is one that we have emphasized in other work, since it entails different shapes of the temporal generalization function. It remains true, however, that variation in only one of these would still result in a symmetrical peak function. When variability occurs in both, then some asymmetry results in the shape of the temporal generalization function, with a higher right tail. The degree of positive skew in the function reflects the relative contribution of two or more sources of variance. If the two sources contribute about equally, positive skew is maximal; if they contribute unequally, it is reduced. A final possibility for symmetrical variance may not be ruled out but is unlikely: namely, two or more sources of variance with opposing skew.

\section{REFERENCES}

Catania, A. C. (1970). Reinforcement schedules and psychophysical judgements: A study of some temporal properties of behavior. In W. N. Schoenfeld (Ed.), The theory of reinforcement schedules (pp. 142). New York: Appleton-Century-Crofts.

Church, R. M., \& Gibbon, J. (1982). Temporal generalization. Journal of Experimental Psychology: Animal Behavior Processes, 8 , 165-186.

GibBon, J. (1981). On the form and location of the psychometric bisection function for time. Journal of Mathematical Psychology, 24, 58-87.

Gibbon, J. (1991). Origins of scalar timing theory. Leaming \& Morivation, 22, 3-38.

Gibbon, J., * BAlsAm, P. (1981). Spreading association in time. In C. M. Locurto, H. S. Terrace, \& J. Gibbon (Eds.), Autoshaping and conditioning theory (pp. 219-253). New York: Academic Press.

Gibbon, J., CHurCh, R. M. (1984). Sources of variance in information processing theories of timing. In W. L. Roitblat, T. G. Bever, \& H. S. Terrace (Eds.), Animal cognition (pp. 465-488). Hillsdale, NJ: Erlbaum.

Gibbon, J., a Church, R. M. (1990). Representation of time. Cognition, 37, 23-54.

Gibbon, J., Church, R. M., Meck, W. H. (1984). Scalar timing in memory. In J. Gibbon \& L. G. Allan (Eds.), Annals of the New York Academy of Sciences: Timing and time perception (pp. 52-77). New York: New York Academy of Sciences.

Labarbera, J. D., \& ChurCh, R. M. (1974). Magnitude of fear as a function of expected time to an aversive event. Animal Learning \& Behavior, 2, 199-202

LibBy, M. E., \& ChURCH, R. M. (1975). Fear gradients as a function of the temporal interval between signal and aversive event in the rat. Journal of Comparative \& Physiological Psychology, 88, 911-916. 
Meck, W. H., ChuRch, R. M. (1984). Simultaneous temporal processing. Joumal of Experimental Psychology: Animal Behavior Processes, 10, 1-29.

Olton, D. S., Wenk, G. L., Church, R. M., \& Meck, W. H. (1988), Attention and the frontal cortex as examined by simultaneous temporal processing. Neuropsychologia, 26, 307-318.

ROBERTS, S. (1981). Isolation of an internal clock. Journal of Experimental Psychology: Animal Behavior Processes, 7, 242-268.
Stein, L., Sidman, M., \& Brady, J. V. (1958). Some effects of two temporal variables on conditioned suppression. Journal of the Experimental Analysis of Behavior, 1, 153-162.

(Manuscript received July 30, 1990; revision accepted for publication January 18, 1991.) 